\title{
RELATIONSHIP BETWEEN DURATION OF UNTREATED PSYCHOSIS AND COGNITIVE FUNCTIONS USING MODIFIED SCORS (SCHIZOPHRENIA COGNITION RATING SCALE) IN SCHIZOPHRENIA PATIENTS IN SAIFUL ANWAR GENERAL HOSPITAL
}

\author{
Dearisa Surya Yudhantara ${ }^{1}$; Laksmi Muliawati²; Zamroni Afif ${ }^{3}$ \\ Correspondence: drdsyudhantara.fk@ub.ac.id \\ ${ }^{1}$ Psychiatry Department Medical Faculty Brawijaya University, ${ }^{2}$ Medical Faculty Brawijaya University, ${ }^{3}$ Neurology Department Medical \\ Faculty Brawijaya University/ Saiful Anwar General Hospital, Indonesia
}

\section{ABSTRACT}

Mental health is a significant health problem in the world, including Indonesia. Lack of understanding and concern for the community, limitations and unequal distribution of mental health service provider also contribute to obstacles to increase public understanding and concern for mental health. This problem will give an impact on the difficulty of patients in accessing care and treatment. The emergence of the phenomenon of Duration of Untreated Psychosis (DUP) or untreated psychosis in society contributes to the worsening of the disease course of schizophrenic patients. One of the main clinical manifestations seen in schizophrenic patients is a decline in cognitive function. SCoRS is present as an easy and effective instrument in quantitatively measuring cognitive function. In the study used a modified SCoRS instrument that was more adapted to Indonesian's culture. This study was conducted to determine the relationship between the duration of untreated psychosis and cognitive function using modified SCoRS, especially in schizophrenic patients at Saiful Anwar General Hospital. The research method used observational analytic with cross-sectional approach. Selection of research subjects based on inclusion and exclusion criteria. Then do the appropriate history taking and psychiatric examination. Correlation analysis using Spearman to determine the relationship of variable duration of psychosis without therapy and cognitive function assessed using SCoRS modification ( $p<0.05)$. The results prove that there is a significant relationship between the variable duration of therapy without therapy and cognitive function variables assessed using SCoRS modification with a weak correlation level (correlation coefficient 0.340).

Keywords: Duration of Untreated Psychosis (DUP), cognitive function, modified SCoRS (Schizophrenia Cognition Rating Scale).

\section{Article History:}

Received: January 2, 2021

Accepted: February 18, 2020

Published: March 30, 2021
Cite this as: Yudhantara, D.S, Muliawati, L, Afif, Z.. Relationship between duration of untreated psychosis and cognitive functions using modified SCORS (Schizophrenia cognition rating scale) in schizophrenia patients in Saiful Anwar General Hospital. Journal of Psychiatry Psychology and Behavioral Research; 2021.1:4-7.

\section{INTRODUCTION}

Mental health still becomes a quite significant problem worldwide including Indonesia. The lack of understanding and awareness toward mental health among society also contributes to the increasing number of schizophrenia cases in Indonesia. The limitation and unbalanced distribution of mental health service provider also create another problem in efforts to increase social understanding and awareness toward mental health. Furthermore, this particular problem will impact on patients with a mental health problem to access treatment and medication. ${ }^{1}$ In some past researches, there was mentioned a DUP or Duration of Untreated Psychosis which occurred within society as a consequence from schizophrenia diagnose difficulty caused by overlap between mental symptoms and behaviour in some groups of people who suffer a high risk of schizophrenia. Other factors in the social environment related to individual condition, interpersonal, and social process also contribute in postpone of medical treatment. ${ }^{2}$

One of the main clinical manifestation seen on schizophrenia patients is derivation of cognitive function which affect psychosocial function and low quality of life. ${ }^{3}$ Derivation of cognitive function on schizophrenia can be measured quantitatively, one of them is by using SCoRS. This instrument is very easy and effective in measuring schizophrenia patient's cognitive function quantitatively. ${ }^{4}$ In this experiment we used modified SCoRS instrument. 
Based on the analysis above, we need to know whether there is a correlation between the duration of untreated psychosis and cognitive function using modified SCoRS on schizophrenia patients. Therefore, we can figure out when is the optimum time to initiate the therapy. Also, deviation of psychosocial function and low quality of life on schizophrenia patients are expected to be minimalize

\section{MATERIAL AND METHOD}

This research used analytic observational research design with the cross-sectional approach. Chosen subjects are under treatment schizophrenia patients in Saiful Anwar General Hospitalwith inclusive criteria below: (1) Diagnosed with schizophrenia based on PPDGJ 3 and DSM-5 (Diagnostic and Statistical Manual of Mental Disorder, 5th Edition); (2) Age 18-60; (3) Patients or families are willing to participate in research. Exclusive criteria on subjects are: (1) Subjects have history of organic mental health disorder and metabolical syndrome; and (2) comorbid to schizoaffective and bipolar disorder.

Sampling was done by quota (consecutive) sampling technique. The result from the calculation mentioned that minimum total sample of 47 was needed in this research.

Before the research begins, the instrument was validated first. After subjects were selected according to inclusive and exclusive criteria, anamnesis and proper psychiatry assessment were proceed to determine cognitive function using the modified ScoRS instrument. After all data were collected, correlation analysis was proceed using spearman to find a correlation between the duration of untreated psychosis and cognitive function which measured by using modified SCoRS $(\mathrm{p}<0,05)$.

\section{RESULT}

\section{Validity Test}

Validity test was conducted to find out whether items in the questionnaire were valid or able to measure needed variables. The result showed that the correlation coefficient value of all items with the total score (riT) $>$ correlation table value $(0,285)$ so it could be used as a data collection tool. Therefore, question items on the modified version of SCoRS evaluation variable were stated as valid.

\section{Reliability Test}

The reliability test was meant to find out reliability and consistency of instrument that used in this research as a tool to measure variables needed. Reliability test was conducted using Cronbach's Alpha technique. Test criteria stated that if Cronbach's Alpha coefficient is $0.952(\geq 0.6)$ then questionnaire items are reliable or consistent in measuring variable measured.

Based on the reliability test result, the value of Cronbach's Alpha $>0.6$. Therefore, question items in the assessment variable of modified SCoRS was stated reliable or consistent in measuring variable measured, so it could be used as a data collection tool in this research.

\section{Normality Test}

Kolmogorov-Smirnov was used as a normality test to find whether the duration of untreated psychosis and cognitive function measured by SCoRS can distribute normally or not. $p$-value was gotten from the variable of the duration of untreated psychosis and measured cognitive function by $S c o R S, 0,000$ and 0,002 respectively. This result showed that $\mathrm{p}<$ level of significant $(\alpha=5 \%)$. Meaning that data of the duration of untreated psychosis and cognitive function measured by SCoRS was deemed could not distribute normally.

\section{Correlation Analysis Test}

Correlation Analysis Test with spearman was done to find out correlation closeness value and whether there was a correlation between the duration of untreated psychosis and cognitive function measured by $S c o R S$. The value of $\mathrm{p}$ was 0,018 with a coefficient correlation of 0,340 . This result shows that $\mathrm{p}<$ level of significance $(\mathrm{a}=5 \%)$. Therefore, there was a significant correlation between duration of untreated psychosis and cognitive function variable measured by $S c o R S$ but it was a weak level of correlation.

\section{DISCUSSION}

The purpose of this research is to find out whether there is a correlation between the duration of untreated psychosis $(D U P)$ and cognitive function in schizophrenia patients measured by modified SCoRS. A significant correlation was found between duration of untreated psychosis $(D U P)$ and cognitive function in schizophrenia patients which measured by modified SCoRS. The probability result was 0,018 which meant less than a level of significance $(\mathrm{a}=5 \%)$. Low level of correlation was shown by the result of the correlation coefficient of 0,340 . This significant result might be caused by the modified instrument of SCoRS which measure respondents' cognitive domain whose affected majorly from DUP duration of memory function, working memory (immediate memory), attention, reasoning and problem solving, language, and motoric skills. Weak correlation might be caused by the existence of some confounder variables in this research that didn't exclude perfectly such are gender, age, and patients' signs and symptoms.

In this research, the exact ratio of male and female gender wasn't determined. From the total respondents, the male was more than female $($ male $=25$ people, female $=23$ people). This was in line with some theories and past researches which mentioned that the long term outcome on female patients was better than on male patients. 5 Confounder variables appeared in ages variable didn't get noticed too much when involving respondents. Wide range of ages from each respondent was a possible caused of weak correlation result in this research (ages range between 18-59). In some theories mentioned that the peak age of schizophrenia happened on male subject was around age 10-25, while on female happened around age 25$35 .^{6}$

Psychosis symptoms that keeps getting more consolidated and becoming harder to do assessment and therapy also become one of the cause. Another factor from respondents who gave information related to onset disease and biased or improper timing the start of treatment was also affected results of this research. Due to a long gap of time when patients were given 
questions and the actual time when actual events happened created a quite big probability that patients might forget.

In previous researches mentioned that there was a correlation between DUP and outcome patients, which was the shorter DUP make a better outcome for the patient. However, this was insignificant in projecting outcome in form of cognitive function. Also mentioned that there was no significant correlation between DUP and most of the neurocognitive domain, but for some specific cognitive functions there might be correlated with $D U P$ duration, for example, cognitive setback/deterioration, cognitive flexibility, speed processing and working memory.

As for cognitive domain that didn't significantly correlate with how long DUP happened might be caused by variation of brain cell maturing development from each individual or because of extent area inside the brain that affected by pathology process related to psychosis condition. The neurocognitive deficit on phase first-episode psychosis (FEP) showed a relatively stable condition. This indicated that neurocognitive deficit could have happened before psychosis symptoms appeared. Furthermore, this created such a broader possibility caused by non-existence of significant correlation between $D U P$ and cognitive function in general. ${ }^{7}$

Meanwhile, for some neurocognitive domain that significantly correlated with duration of DUP can be explained using neurotoxicity theory. The longer the lag time to obtain treatment resulted in the worse derivation of neurocognitive function. The excitotoxic process that happened physiologically changed into pathology process which caused the death of neuron and excess stimulation of glutamate activity. As a result, $\mathrm{Ca}$ canal opens so that $\mathrm{Ca}$ goes into cell excessively. Thus caused increasing of neuron membrane excitation that further activate destructive chemical cascade. From this process, free radicals appeared which destroy cellular components such as organelle cell and membrane cell. The same process also happened to dendrites which had functioned as the post-sinaps target from glutamate. This damage level is what correlated to the derivation of cognitive function. ${ }^{8}$

Concerning the exact duration of DUP that impacted the outcome of the patient especially cognitive patient, there was no information found that could explain it. The first study in DUP classification within a range of 0-7 days, 7-28 days, 28-90 days, 90-365 days, and >365 days.9 Another study on DUP classification turned into 1 month, 3 months, dan 1 year.10 There was also some who classified $D U P$ for $\leq 74$ weeks and $>74$ weeks, $<6$ months dan $>6$ months. 11 From all the preceding studies, there was one same result which was there was no significant correlation between DUP and cognitive function on schizophrenia patients. However, a significant result was obtained where the long duration of $D U P$ and other symptoms appeared as negative symptoms. Meanwhile, in this research, it was decided that 1 year was a cut off from DUP because too many respondents remembered onset timing of their disease and start timing of treatment under years unit.

In this research, a significant correlation between psychosis duration variable without therapy and cognitive function variable measured by modified $S C O R S$ was found. A probability value of 0,018 meant less than the level of significance $(\mathrm{a}=5 \%)$. A weak correlation was also found. It was shown by the value of the correlation coefficient 0,340 .
This might be caused by modified SCoRS instrument which measured cognitive domain of respondent that affected by the duration of DUP such as memory function, working memory (immediate memory), attention, reasoning and problem solving, language, and motoric skills. Another reason why there was a weak correlation between schizophrenia symptoms and cognitive of schizophrenia patients was that they became an independent variable, so they could not affect each other directly.

Psychosis symptoms that kept getting consolidated as time goes on and became more difficult to be measured and treated were also one of the reasons. Factor from the respondent who gave information related to onset timing of their symptoms and biased or improper initial timing of treatment were also affected the result of this research because they might forget some or even most of what happened since it happened a long time ago.

\section{CONCLUSION}

Based on the research result of the correlation between psychosis duration without therapy and cognitive function in schizophrenia patients by using modified SCoRS conducted July-September 2018 in Saiful Anwar General Hospital Malang, the conclusions are as follow:

1. There was a significant correlation between psychosis duration variable without therapy and cognitive function variable measured by modified $S c o R S$ but it was weak. It was shown by the value of $\mathrm{p} 0,018$ which meant $p<$ level of significant $(\alpha=5 \%)$. Value of correlation coefficient 0,340 showed that there was a weak but positively significant correlation between psychosis duration variable without therapy and value from modified ScoRS.

2. There was a derivation of schizophrenia patients' cognitive function measured by modified SCoRS on schizophrenia patients without therapy on psychosis duration $(D U P)$. Patients with $D U P<1$ year got an average score of 28,43 by using modified $S C O R S$, while patients with $D U P>1$ year got an average score of 32,95 also by using modified SCoRS. Average total score from modified SCoRS instrument on patients with $D U P$ was 30,31 . The higher value result from modified ScoRS, the bigger derivation of cognitive function on patients.

\section{REFERENCES}

1. Kementerian Kesehatan Republik Indonesia. Peran Keluarga Dukung Kesehatan Jiwa Masyarakat. Jakarta : Biro Komunikasi dan Pelayanan Masyarakat, Kementerian Kesehatan RI; 2016.

2. Albert N, Melau M, Jensen H, et al. The effect of duration of untreated psychosis and treatment delay on the outcomes of prolonged early intervention in psychotic disorders. $n p j$ Schizophr; 2017. 3: 34. https://doi.org/10.1038/s41537017-0034-4

3. Arsova S, Barsova GK. Patients with Schizophrenia and Social Contacts. Open Access Maced J Med Sci; 2016 Sep. 15;4(3):388-391. doi: 10.3889/oamjms.2016.084. Epub 2016 Jul 21. PMID: 27703560; PMCID: PMC5042620. 
4. Mazhari S, Ghafaree-Nejad AR, Soleymani-Zade S, Keefe RSE. Validation of the Persian version of the Schizophrenia Cognition Rating Scale (SCoRS) in patients with schizophrenia. Asian J Psychiatr; 2017 Jun. 27:12-15. doi: 10.1016/j.ajp.2017.02.007. Epub 2017 Feb 14. PMID: 28558882.

5. Ran MS, Mao WJ, Chan CL, Chen EY, Conwell Y. Gender differences in outcomes in people with schizophrenia in rural China: 14-year follow-up study. Br J Psychiatry; 2015 Apr. 206(4):283-8. doi: 10.1192/bjp.bp.113.139733. Epub 2015 Jan 8. PMID: 25573398; PMCID: PMC4381189.

6. Sadock BJ, Sadock VA, \& Ruiz P. Kaplan and Sadock's Synopsis of Psychiatry : Behavioral Sciences/Clinical Psychiatry, $11^{\text {th }} \mathrm{Ed}$. Philadelphia : Lippincott Williams \& Wilkins; 2014.

7. Allott K, Fraguas D, Bartholomeusz C, Díaz-Caneja C, Wannan C, Parrish E, Rapado-Castro M, et al. Duration of untreated psychosis and neurocognitive functioning in first-episode psychosis: A systematic review and metaanalysis. Psychological Medicine; 2018. 48(10), 15921607. doi:10.1017/S0033291717003002.

8. Lahti AC, Reid MA. Is there evidence for neurotoxicity in the prodromal and early stages of schizophrenia? Neuropsychopharmacology; 2011 Aug. 36(9):1779-80. doi: 10.1038/npp.2011.83. PMID: 21753798; PMCID: PMC3154114..

9. Harrigan SM, McGorry PD, Krstev H. Does treatment delay in first-episode psychosis really matter? Psychol Med; $2003 \quad$ Jan. 33(1):97-110. doi: 10.1017/s003329170200675x. PMID: 12537041.

10. Crumlish N, Whitty P, Clarke M, Browne S, Kamali M, Gervin M, McTigue O, Kinsella A, Waddington JL, Larkin C, O'Callaghan E. Beyond the critical period: longitudinal study of 8-year outcome in first-episode non-affective psychosis. Br J Psychiatry; 2009 Jan. 194(1):18-24. doi: 10.1192/bjp.bp.107.048942. PMID: 19118320.

11. Kane JM, Robinson DG, Schooler NR, Mueser KT, Penn DL, Rosenheck RA, Addington J, Brunette MF, Correll CU, Estroff SE, Marcy P, Robinson J, Meyer-Kalos PS, Gottlieb JD, Glynn SM, Lynde DW, Pipes R, Kurian BT, Miller AL, Azrin ST, Goldstein AB, Severe JB, Lin H, Sint KJ, John M, Heinssen RK. Comprehensive Versus Usual Community Care for First-Episode Psychosis: 2-Year Outcomes From the NIMH RAISE Early Treatment Program. Am J Psychiatry; 2016 Apr. 1;173(4):362-72. doi: 10.1176/appi.ajp.2015.15050632. Epub 2015 Oct 20. PMID: 26481174; PMCID: PMC4981493. 